\title{
FORMAÇÃO PARA O ENSINO DE DANÇA: pensamento de professores
}

\author{
Formation for the teaching of dance: teachers' thought
}

\author{
Luciana Rosa Gualda ${ }^{a}$, Ana Maria Falcão de Aragão Sadalla ${ }^{b}$
}

a Bacharel e licenciada em Dança pela Universidade Estadual de Campinas, Campinas, São Paulo - Brasil. e-mail: lurgualda@yahoo.com.br

b Professora da Faculdade de Educação da Universidade Estadual de Campinas, Campinas, São Paulo - Brasil. e-mail: anaragao@terra.com.br

\section{Resumo}

A busca pela estética e pela perfeição técnica faz com que a dança perca o seu sentido expressivo e passe a ser a pura mecânica de execução de movimentos, destruindo a liberdade na dança e limitando as capacidades imaginativas e criativas dos alunos. Alguns profissionais propõem um ensino de dança baseado na reflexividade, no qual o corpo é visto como uma rica fonte de conhecimento e que, quando não objetificado, pode ser o lugar para a reflexão crítica, propondo desvincular a rigidez técnica em busca de uma libertação na dança e de um respeito à diversidade dos corpos. Foram realizadas entrevistas com cinco docentes de notória experiência nesta forma de ensino com o objetivo de analisar sua concepção de ensino e de trabalho com o corpo. Se por um lado os professores entrevistados acreditam que a licenciatura é importante para a formação, por outro, os pesquisadores afirmam que os professores de dança não estão preparados para atuar nas escolas. Este artigo vem propor uma discussão e reflexão sobre ensino de dança, tendo como foco principal o entendimento de que este ensino deve sempre buscar o desenvolvimento da criatividade e expressividade, almejando uma maior proximidade entre educação e dança na formação de professores e uma valorização do ensino de dança nas escolas regulares.

Palavras-chave: Formação em dança; Ensino de dança; Dança nas escolas; Pensamento de professores.

Rev. Diálogo Educ., Curitiba, v. 8, n. 23, p. 207-220, jan./abr. 2008 


\section{Abstract}

The search for aesthetics and technical perfection makes dance loose its expression sense and turn into pure mechanical execution of movements, destroying, this way, the possibility of freedom and also limiting the students' imaginative and creative capacities. Some professionals propose the teaching of dance based on reflection and defend that the body should be seen as a rich source of knowledge that, when not regarded as an object, can be the place where critical reflection happens. Such approach implies the rupture with technical inflexibility in favor of the search for both a state of freedom in dance and respect to the diversity of bodies. Five teachers with recognized experience in such a way of teaching dance were interviewed so that their conception regarding teaching and the work with the body could be analyzed. If on the one hand the interviewed teachers believe that teacher education is important for their formation, on the other researchers claim that the dance teachers are not prepared to act in schools. This article proposes further discussion and reflection about the teaching of dance, having as its is main focus the view that such teaching should always aim at the development of creativity and expression capacity in order to reach a bigger proximity between Education and dance as far as teacher formation is concerned, as well as a greater valorization of the teaching of dance in regular schools.

Keywords: Formation in dance; Teaching of dance; Dance in schools; Teachers' thought.

Os atuais cursos de dança, tanto de academias quanto em universidades, têm, em sua maioria, pensado o corpo do bailarino em termos técnicos, como um instrumento que executa movimentos. As aulas de técnica de dança são extremamente valorizadas e os estilos trabalhados seguem técnicas codificadas e sistematizadas. Essa situação é constatada por Marques (2001, p. 27):

Em mundos aparentemente distantes e distanciados, às vezes até mesmo incomunicáveis, escolas de dança e ensino formal indiretamente se retroalimentaram no que diz respeito aos conceitos de arte e ensino. O tradicionalismo que volta a ter força nas escolas de dança encontra reforço em grande maioria das escolas formais

Rev. Diálogo Educ., Curitiba, v. 8, n. 23, p. 207-220, jan./abr. 2008 
que ainda não abandonaram esta filosofia de ensino (o enciclopedismo, o tecnicismo, o aluno tabula rasa, etc.). Por outro lado, a idéia de dança e ensino que prevalece entre alunos e professores dessas escolas - mesmo as que não têm essa disciplina como componente curricular pode ser remetida à do século XVIII. (virtuosismo, espetáculo, aprimoramento técnico etc.).

Os bailarinos buscam cada vez mais a perfeição técnica. O corpo tornou-se um instrumento a ser controlado e dominado, buscando sempre superar os limites físicos. Não existe a preocupação com o processo criativo corporal individual, nem em traçar relações entre corpo, dança e sociedade.

$\mathrm{Na}$ maioria das aulas de dança, principalmente de técnica, os alunos devem executar seqüências de movimentos criadas pelos professores ou coreógrafos e que têm como objetivo chegar a uma forma estética de acordo com o método trabalhado. Os alunos são classificados de acordo com a habilidade técnica na execução dos movimentos. Essa busca pela forma faz com que a movimentação se classifique como certa e errada, propiciando aos alunos a descoberta de qualidades, mas condenem possíveis defeitos nos corpos dos alunos que acabam por atrapalhar na execução dos movimentos.

Essa busca pela estética e pela perfeição técnica faz com que a dança perca o seu sentido expressivo e passe a ser a pura mecânica de execução de movimentos. O ensino de técnica destrói a liberdade na dança e limita as capacidades imaginativas e criativas dos alunos porque eles não são estimulados a criar novos movimentos, mas sim a reproduzir os movimentos determinados pela seqüência ou pelo professor. Nesse caso então, não há uma preocupação com o processo, mas sim com o produto final que é determinado pela estética do método.

Diante deste quadro, alguns profissionais propõem um ensino de dança no qual o corpo é visto como uma rica fonte de conhecimento e que, quando não objetificado, pode ser o lugar para a reflexão crítica. Esses cursos procuram se desvincular de uma rigidez técnica em busca de uma libertação na dança, e de um respeito à diversidade dos corpos. Nessa proposta, não há uma valorização exclusiva com a perfeição visual e técnica. A idéia não afasta o ensino da técnica, porém passa-se a pensar a dança valorizando as experiências pessoais e o processo criativo aliado ao fato de o corpo estar modelado pela sociedade na qual ele está inserido.

Os pesquisadores dessa área afirmam que esse tipo de ensino possibilita o enriquecimento das qualidades críticas, criativas e morais dos alunos. Segundo Shapiro (1998, p. 41), "O objetivo da experiência de aprendizagem se desloca de conhecer o vocabulário do movimento, em nome da criação da dança, para compreender a si mesmo, aos outros e a um mundo mais amplo para a possibilidade de mudança".

Rev. Diálogo Educ., Curitiba, v. 8, n. 23, p. 207-220, jan./abr. 2008 
Uma das possíveis aplicações dessa proposta de ensino está no trabalho com dança feito em escolas, tendo como ponto de partida o ensino oferecido nos cursos de licenciatura.

Para a Lei de Diretrizes e Bases n. 9394/96, a Arte é reconhecida como disciplina escolar. Segundo os Parâmetros Curriculares Nacionais, a arte é considerada "uma área curricular com conteúdos específicos e uma função tão importante quanto às outras áreas de conhecimento" (MORANDI, 2005, p. 12). Além disso, o documento de arte dos PCN indica que o ensino de artes deve variar suas linguagens artísticas e abarcar dança, música, artes cênicas e artes visuais, propiciando ao aluno vivenciar e aprofundar seu conhecimento em diferentes formas artísticas.

Ainda para Morandi (2005, p. 77), "O papel da arte e da dança nas escolas seria justamente o de possibilitar a transformação contínua da existência, mudar referências, proporcionar novos e múltiplos olhares sobre o mundo". Segundo esta mesma autora, a arte permite "uma compreensão do mundo de forma mais sensível e mais significativa".

Porém, o ensino de dança na escola ainda encontra muitos obstáculos como, por exemplo, a falta de um espaço adequado para as atividades corporais; o preconceito por parte dos alunos, principalmente os meninos; a não valorização desta atividade pelos professores e diretores; entre outras. Mas o que muitos pesquisadores têm constatado é que os professores de dança não estão preparados para atuar em outro contexto que não seja o de academia. Ou seja, os professores de dança ainda, em sua maioria, reproduzem apenas os conceitos técnicos e desconhecem a importância da dança nesse aspecto reflexivo. Strazzacappa (2003, p. 275) descreve o perfil dos alunos do curso de dança de uma universidade:

É comum os alunos do curso de dança realizarem a formação de professor apenas como uma segunda opção. Iniciam as disciplinas pedagógicas sem muito entusiasmo, pois dançar profissionalmente lhes é mais importante. Depois de formados bacharéis e tentarem a vida profissionalmente, começam a ministrar aulas e no exercício da docência, deparam-se com a falta de preparo e recorrem à complementação de estudos, reingressando para concluir a licenciatura.

$\mathrm{Na}$ tentativa de compreender com mais clareza as características desse novo paradigma no ensino da dança, desenvolvemos uma pesquisa que tinha como objetivo analisar o que pensam e quais os objetivos dos professores que ministram essas aulas. Entendemos como fundamental abordar o que Sadalla et al. (2000) definem como "sabedoria docente", que é a junção de todos os conhecimentos adquiridos pelo professor durante a sua vida, portadora de crenças, concepções, ideais, modos de ação, procedimentos e hábitos, e que justificam as ações.

Rev. Diálogo Educ., Curitiba, v. 8, n. 23, p. 207-220, jan./abr. 2008 
Sendo assim, acreditamos que entrevistar cinco docentes de notória experiência nesta forma de ensino seria o procedimento mais adequado para clarear as características desse ensino. Os professores participantes foram selecionados seguindo indicações da literatura ou de seus pares e, de acordo com os seguintes critérios: professores que atuam no Estado de São Paulo; sólida formação em dança (aperfeiçoamento, especialização ou pós-graduação); ampla experiência com dança educativa.

Para a entrevista, foi feito um roteiro organizado a partir do aprofundamento teórico obtido por meio da literatura, focalizando a concepção de ensino, a dança na escola e a formação dos alunos de graduação. As entrevistas tiveram a duração de, aproximadamente, uma hora e foram audiogravadas e, depois, transcritas, sendo analisadas segundo a metodologia proposta por Bardin (1977), a Análise de Conteúdo, dando origem às seguintes categorias:

\section{Concepção de ensino}

1. Ensinar Movimentos Específicos

1.1 Vantagens

1.2 Desvantagens

2. Ensinar a partir do Movimento Corporal

3. Ensinar na Escola Regular

4. Ensinar Reelaborando Técnicas

5. Relação Professor-Aluno

5.1 Fundamental para o Processo Ensino-Aprendizagem

5.2 Papel do professor

\section{Concepção de trabalho com o corpo}

1. Todo Corpo é Capaz de Dançar

Inexistência do Tipo Físico Ideal

Importância da Diversidade de Corpos

2. Dança como Promoção do Autoconhecimento

\section{Concepção de ensino}

Como já apontado inicialmente, a maioria dos cursos de dança tem preservado uma visão tecnicista do ensino, onde o corpo é visto como objeto e a execução dos movimentos está vinculada a uma perfeição técnica e estética.

As entrevistas demonstraram que na concepção de ensino das professoras, a promoção da expressividade por meio da dança torna-se o principal objetivo. Sendo assim, as questões buscaram compreender a utilização das técnicas para que o ensino de dança atinja esse objetivo expressivo.

Rev. Diálogo Educ., Curitiba, v. 8, n. 23, p. 207-220, jan./abr. 2008 
As falas mostram que algumas professoras acreditam que não é necessário ensinar seqüências de passos prontos criadas pelos próprios professores, mas, sim, partir da movimentação dos alunos. Porém, pudemos perceber que, assim como afirma Nanni (2003), a maioria das falas demonstrou que o ensino de dança deve unir conhecimento técnico e expressividade.

A autora explica que a dança deve unir os dois aspectos míticos: apolíneo e dionísico. Ou seja, a dança deve trabalhar (na perspectiva de Dionísio) a sensibilidade, a expressão e suas possibilidades de ampliação e a comunicação corporal para a livre flutuação das emoções; ao mesmo tempo em que não se afasta da técnica e de conteúdos formais (na perspectiva de Apollo). Dessa forma, o corpo passa a ser trabalhado de forma ampla e total favorecendo o desabrochar do corpo imanência e do corpo transcendência.

Ao facilitar perspectivas à ação criadora, em consonância com o jogo da subjetividade do indivíduo, a dança libera o aspecto lúdico, a alegria, o prazer, a imaginação criadora, fatores que dão consciência às vivências corporais enquanto metáforas corporais, ou seja, linguagem nãoverbal, propiciando as interações sócio-afetivas desses atores sociais. (NANNI, 2003, p. 195).

É importante ressaltar que nem sempre o trabalho técnico está sendo identificado. Cabe ao professor saber a necessidade e a estratégia para utilizá-lo. Uma justificativa para a execução de seqüências de passos é proporcionar o conhecimento de mais uma possibilidade de movimento, não apenas aqueles criados pelos próprios alunos. Além disso, as entrevistadas apontam que as seqüências de passos são importantes para que o aluno compreenda a linguagem. A execução de seqüências de movimentos muitas vezes acontece como uma preparação para o corpo. É necessário que os alunos tenham o corpo tecnicamente preparado para que eles possam executar os movimentos que quiserem e consigam, assim, se expressar. Essa preparação corporal torna-se, então, um subsídio para a criação e não para a simples reprodução. Assim sendo, os movimentos prontos não devem ser levados ao palco como coreografias. Isso mostra que o trabalho técnico é um caminho, mas não um fim.

Também foi levantada a questão do desafio. Para as entrevistadas, as seqüências de passos devem promover o desafio ao aluno, destacando que existe uma determinada expectativa por parte dos alunos em executar coreografias. Faz parte do imaginário dos alunos a visão de que dançar é executar seqüências de movimentos. Então, muitas vezes, os professores criam seqüências de passos para satisfazer esse desejo dos alunos.

Rev. Diálogo Educ., Curitiba, v. 8, n. 23, p. 207-220, jan./abr. 2008 
Em algumas falas, encontramos a justificativa de que o trabalho técnico proporciona ao aluno trabalhar a concentração e atenção para o movimento. Além disso, as professoras julgam importante que os alunos conheçam algumas técnicas. Isso não significa que eles tenham que executar os movimentos com uma perfeição técnica, mas sim conhecer e vivenciar algum tipo de vocabulário no corpo.

Entretanto, sendo o aluno um profissional da dança, é necessário que ele saiba reproduzir movimentos, pois essa deve ser uma das competências do bailarino. Porém, é importante ressaltar que essa é apenas uma das competências, mas não pode ser a única. Uma das desvantagens do ensino de técnicas é a mecanização dos movimentos, ou seja, os alunos ficam fixados no código e não conseguem se desprender dele para dançar.

Para Fiamoncini (2002-2003, p. 61), é preciso lidar com o ensino de técnicas, sem impedir o aflorar da criatividade e da expressividade, pois o excesso de técnicas pode fazer com que fiquem esquecidos "os pensamentos, as necessidades e os sentimentos das pessoas, o que pode ocasionar-lhes uma falta de sentido para continuar dançando".

Além disso, foi apontado também que dependendo da maneira como o professor aborda ensino de técnica, ele pode estar contribuindo para afastar os alunos. Isso porque é necessário que o aluno se identifique com a técnica e que as técnicas utilizadas tenham uma relevância social e o comprometimento com os alunos para que eles possam se apropriar dela e ela passe, então, a ter um significado para quem os faz, caso contrário, a dança pode se tornar uma execução mecânica de movimentos e perder o sentido expressivo.

Dessa forma, a dança deixa de ser apenas uma manifestação artística e passa a ser um lugar para a reflexão crítica. O foco central torna-se o autoconhecimento e o conhecimento social.

Para Marques (2005, p. 32), os conteúdos trabalhados nas aulas de dança têm que estar em conexão com o contexto dos alunos: "o contexto dos alunos é um dos interlocutores para o fazer-pensar a dança, pois garante a relação entre o conhecimento em dança e as relações sócio-político-culturais dos mesmos em sociedade".

O conteúdo centrado na realidade e no contexto dos alunos deve ser transformado pelo professor de forma consciente e problematizadora para que o aluno entenda a dança como um processo individual, coletivo e social no qual todos podem produzir saberes e conhecimentos.

Pudemos perceber que, para as entrevistadas, o relacionamento professor-aluno é fundamental no processo ensino-aprendizagem. Algumas falas citam como importante à relação professor-aluno-conhecimento. Nesta interação, é importante que o professor trabalhe tentando contagiar os alunos para o

Rev. Diálogo Educ., Curitiba, v. 8, n. 23, p. 207-220, jan./abr. 2008 
conhecimento. Ainda, é necessário que haja uma proximidade e que o professor tenha a sensibilidade de escutar os alunos para que eles se sintam parte ativa no processo de ensino e aprendizagem. Contudo, é importante ressaltar que as professoras colocam isso como um desafio e como o papel do professor. Sendo assim, o professor deve mobilizar e contagiar o máximo os alunos para que o processo educativo promova transformações dos alunos.

Existe um pensamento que as pessoas acreditam que não sejam capazes de dançar por não ter um conhecimento em dança e isso acaba afastando os alunos. E os profissionais costumam acreditar que quem nunca fez nenhuma técnica de dança não é capaz de dançar. Essa crença pode ser conseqüência de uma realidade brasileira onde existe pouco acesso à cultura. Um dos caminhos para reverter essa situação seria a valorização de atividades artísticas, e especificamente da dança, nas escolas regulares.

Embora a lei n. 9394/96 garanta o ensino de arte como componente curricular obrigatório da educação básica, representado pelas várias linguagens artísticas, raramente a dança ou a expressão corporal é abordada.

Interessados nos benefícios que o ensino de dança pode propiciar aos alunos, alguns profissionais da área lutam para que ela seja inserida na escola. Strazzacappa (2001, p. 71) explica:

\begin{abstract}
A introdução de atividades corporais artísticas na escola, ou seja, a realização de trabalhos de dança-educativa ou dança-expressiva, como são comumente chamadas, tem mudado significativamente as atitudes de crianças e professores na escola. A dança no espaço escolar busca o desenvolvimento não apenas das capacidades motoras das crianças e adolescentes, como de suas capacidades imaginativas e criativas.
\end{abstract}

Para Marques (2005, p. 23), a escola pode "fornecer parâmetros para sistematização e apropriação crítica, consciente e transformadora dos conteúdos específicos da dança e, portanto da sociedade". Pregnolatto (2004) explica que o ensino de arte propicia a transformação e expressão da criatividade, que é fundamental para que possamos construir relacionamentos humanos que estabeleçam uma atuação consciente dos seres entre si e destes com o meio. Segundo Fiamoncini (2002-2003, p. 69), "temos observado que o despertar para a arte, para a sensibilidade, tem finalidade educacional na medida em que pretende desenvolver com o aluno a autonomia, a crítica, e a ética".

Para as professoras entrevistadas, a arte e, mais especificamente, a dança é um conhecimento tão importante quanto qualquer outro conhecimento presente na escola. Sendo a escola um espaço de formação geral e não de

Rev. Diálogo Educ., Curitiba, v. 8, n. 23, p. 207-220, jan./abr. 2008 
formação artística, o objetivo do ensino de dança na escola é o aluno vivenciar a dança como arte. Então, as atividades de dança devem ser trabalhadas com o foco na expressividade dos alunos por meio do corpo. Sendo assim, uma das falas sugere que a introdução da dança na escola seja feita de maneira mais ampla, sob a perspectiva de movimento para que os alunos não criem repulsas e expectativas equivocadas.

Pereira (1997, p. 55) explica ainda que o professor não deve se prender a perfeição técnica dos movimentos, mas sim, estimular a subjetividade da dança:

O trabalho com estilos e técnicas devem ter por objetivo levar a pessoa a tomar consciência de sua própria potencialidade, melhorar sua capacidade de se comunicar, incentivar a sua criatividade, do conhecimento dos estilos históricos e a compreensão da função social que esses estilos tiveram ao longo dos tempos, servir como instigadora de pesquisa sobre o entendimento das dinâmicas destas danças e as formas que o corpo e o movimento assumiram e assumem no tempo e no espaço.

Para atingir esse objetivo, o professor de dança deve observar e preservar as potencialidades dos alunos. Não existe um método ideal de trabalho. É necessário que o professor observe a realidade corporal dos alunos e trabalhe com as linguagens das crianças, permeando com o conteúdo que ele quer abordar.

Marques (2005) e "para relaxar", ou ainda, "para conter a agressividade". Ou, também, para desenvolver a coordenação motora. As aulas de dança nas escolas também tendem a se resumir em ensaios de coreografias para mostrar nos eventos da escola.

Segundo as professoras entrevistadas, existe um consenso de que a introdução de atividades de dança nas escolas ainda é muito recente e está muito longe do que eles acreditam ser o ideal. Contudo, os problemas não se referem apenas à estrutura da escola, mas também ao tipo de formação recebida pelos alunos, em especial, os alunos de licenciatura. E algumas falas apontam que a realidade da formação é precária porque os alunos só estão preparados para dar aulas de técnica.

Para Moura (2001), a situação de despreparo dos professores é ainda mais grave. Em sua pesquisa, ela entrevista professoras que declaram o começo da carreira de professora na adolescência. Estas reproduziam os ensinamentos técnicos adquiridos concomitantes à sua formação como bailarinas. Sem dúvida, essas precoces professoras não tinham nenhum preparo para estimular esse tipo de ensino.

Rev. Diálogo Educ., Curitiba, v. 8, n. 23, p. 207-220, jan./abr. 2008 
Atualmente temos, no Brasil, 15 cursos superiores de dança, sendo que entre esses, 13 oferecem o curso de licenciatura em dança. No estado de São Paulo, são 4 cursos superiores de dança e 3 desses cursos oferecem a licenciatura em dança.

Além dos professores não conseguirem ainda um ingresso nas escolas de maneira formal, pois os concursos públicos exigem o bacharelado em educação artística, ainda são poucos os profissionais de dança que possuem curso de licenciatura. Como já apontado anteriormente, Strazzacappa (2003) explica que os alunos de graduação priorizam a formação como bacharelado. Ao ingressarem na vida profissional, deparam-se com a docência e sentindo-se despreparados, reingressam para concluir a licenciatura e complementar os estudos pedagógicos.

O curso de licenciatura e, também o estágio, proporcionam aos alunos uma vivência e uma preparação diferenciada para o ensino. Sendo assim, os alunos que passam pela licenciatura estão mais preparados para lidar com a realidade do ensino. Esta formação específica é vista, pelas professoras entrevistadas, como uma preparação importante para a carreira de professor de dança.

Entretanto, é importante ressaltar que a carga horária de estágio na licenciatura não é satisfatória. O estágio ainda não é suficiente para garantir a formação ideal. E também é importante destacar que as professoras acreditam que as vivências ao longo da vida também são importantes para a formação do professor. Então, não apenas o estágio garantirá a qualidade da formação do professor de dança.

Para Barreto (2001, p. 144), o ensino de artes na escola tende a se tornar "o exercício de reproduzir e transmitir habilidades técnicas, informações sobre a arte desconectadas da realidade dos educandos e da proposta pedagógica das escolas". Existe também uma preocupação em integrar uma formação artística com uma prática pedagógica, pois existe um distanciamento entre o que se propõe no bacharelado e na licenciatura. Neste caso, os alunos vivenciam um conflito da formação artística com o que é proposto pela prática pedagógica. As professoras ressaltam que a interação entre a dança e a prática pedagógica é muito recente então ainda não há uma estrutura que permita um planejamento de conteúdos a serem ensinados ao longo dos anos escolares. Isso faz com que os professores se sintam muito inseguros.

Porém, é importante destacar que há falas que demonstram que a licenciatura é uma formação desnecessária e que se tornar professor é construído ao longo da vida, não sendo necessário uma formação específica focalizada na prática educacional.

\section{Concepção de trabalho com o corpo}

Ao longo da história da dança, foram estabelecidas regras rígidas com relação à estética corporal dos profissionais da área. Há um biotipo físico que deve ser seguido. Segundo Moura (2001, p. 09):

Rev. Diálogo Educ., Curitiba, v. 8, n. 23, p. 207-220, jan./abr. 2008 
Às bailarinas clássicas exigia-se - como exige até hoje um corpo magro (até mesmo esquelético), longilíneo, sem muitas curvas que denunciassem a mulher dentro do tutu. As exigências aos profissionais passaram a fazer parte do discurso de todos os que atuam na área, em estilos e linguagens de dança diferentes. Em uma sala de aula, pouco importa quem queira dançar profissionalmente, as meninas que ali estão, têm de ser brancas, magras, de quadris estreitos e coxas finas.

A partir das falas, é possível notar que, para as professoras entrevistadas, não há uma exigência quanto a um tipo físico ideal. Qualquer corpo é capaz de dançar. É importante ressaltar que existem modelos de corpo ideal, porém, o tipo físico não é um pré-requisito para a dança.

As professoras ressaltam que a própria identificação com uma estética ou estilo de dança já está relacionada com o aluno. Isso porque quando observamos o corpo no contexto da dança, podemos perceber diferentes valores da cultura de onde ele provém. Isso mostra que além das diferentes histórias de vida, o corpo está marcado por um contexto social. As pessoas estão inscritas em uma determinada sociedade, que possui valores culturais que modelam o nosso corpo. Estes corpos são cheios de significados e valores culturais do nosso tempo e proporcionam um mapeamento emocional de quem somos.

Sendo assim, apesar das diferentes experiências que marcam singularmente nossos corpos, também devemos entendê-los como corpos que têm uma marca histórica, política e social, reflexo da cultura na qual ele está inserido.

Ferreira (2003, p. 103) explica a sua concepção de ensino de dança onde há uma compreensão dessa inserção cultural:

Na tradição ocidental, o corpo na dança é discutido em termos de tamanho, forma, técnica, flexibilidade e sua vida orgânica. Um objeto biológico e fisiológico. Ao contrário, venho propondo uma visão de corpo, primeiro como um objeto marcado pelos valores e significados culturais da nossa época, um veículo de compreensão da opressão, da resistência e da liberação.

As histórias, as experiências e valores dos alunos passam a ser o foco para o ensino. Para Pregnolatto (2004), o ensino que valoriza o universo dos alunos (individual e coletivo) e a vivência corporal desses conteúdos possibilita questionamentos e a ampliação da consciência dos alunos. O corpo passa a ser o lugar para a reflexão crítica na medida em que recebe do ambiente diferentes sentidos significados e os devolvem ao mundo recriados e transformados.

Rev. Diálogo Educ., Curitiba, v. 8, n. 23, p. 207-220, jan./abr. 2008 
Para Santos e Figueiredo (2002-2003), a interação dos alunos nas atividades criativas das aulas de dança ensina a expressão e a comunicação de diferentes corpos e propicia a aceitação e a valorização da diversidade. Isso constitui um fator de enriquecimento e formação da sociedade sendo, portanto, essenciais para o cumprimento da ação educativa.

\section{CONSIDERAÇÕES FINAIS}

Diante das verbalizações das professoras entrevistadas, pudemos perceber que, apesar de a maioria dos cursos de dança ainda manter uma visão de ensino focalizada no ensino de técnicas, já existem novas propostas para o ensino de dança. Pensando nisso, este artigo vem propor um ponto de partida para se discutir e refletir sobre ensino de dança, tendo como foco principal o entendimento de que este ensino deve sempre buscar o desenvolvimento da criatividade e expressividade. $\mathrm{O}$ professor deve estar atento às desvantagens conseqüentes de um ensino exclusivamente técnico para que o ensino de dança não perca o seu objetivo principal que é a expressividade. Sendo assim, a introdução de conteúdos específicos de técnica de dança não deve estar vinculada a uma busca pela perfeição técnica e estética.

Além disso, também foi apontado que dependendo da abordagem do professor, o ensino de técnicas pode afastar os alunos. $\mathrm{O}$ aluno deve ser visto como sujeito ativo e participante do processo ensino-aprendizagem. Em vez de apenas depositar conhecimentos, os professores precisam partir da realidade e da linguagem dos próprios alunos para promover o ensino de dança.

Os modelos e padrões estabelecidos para a dança valorizam o corpoobjeto e excluem a possibilidade de entender os alunos como sujeitos, impedindo o desenvolvimento da criatividade e da expressividade. O ensino de dança que contribui para o autoconhecimento e propicia a interação entre os alunos permite entender e apreciar as diferenças ao mesmo tempo em que contribui para uma reflexão crítica da sociedade e do mundo no qual estamos inseridos. O ensino estará contribuindo para que a dança seja também um lugar para a reflexão crítica na medida em que o professor transforma essa realidade dos alunos de forma consciente e problematizadora.

Por fim, também foi possível perceber que ainda existem dúvidas quanto à qualidade da formação recebida pelos professores de dança. Se por um lado os professores entrevistados acreditam que a licenciatura é importante para a formação, por outro, os pesquisadores afirmam que os professores de dança não estão preparados para atuar nas escolas. Uma das possíveis causas dessa dicotomia é justificada por ser muito recente a interação entre dança e prática pedagógica.

Rev. Diálogo Educ., Curitiba, v. 8, n. 23, p. 207-220, jan./abr. 2008 


\section{REFERÊNCIAS}

BARDIN, Laurence. Análise de conteúdo. Lisboa: Edições 70, 1977.

BARRETO, Débora. Dança... ensino, sentidos, e possibilidades na escola. 2001. 217 f. Dissertação (Mestrado) - Universidade Estadual de Campinas, Campinas, 2001.

FERREIRA, Angela. Dança criativa: uma nova perspectiva do ensino e da criação. In: CALAZANS, Julieta; CASTILHO, Jacyan; GOMES, Simone (Coord.). Dança e educação em movimento. São Paulo: Cortez, 2003. p. 265-271.

FIAMONCINI, Luciana. Dança na educação: a busca de elementos na arte e na estética. Revista Pensar a prática: Revista da PósGraduação em Educação Física, Goiânia, v. 6, p. 59-72, jul./jun. 2002-2003.

MARQUES, Isabel. Ensino de dança hoje: textos e contextos. São Paulo: Cortez, 2001.

Dançando na escola. 2. ed. São Paulo: Cortez, 2005.

MORANDI, Carla Silva Dias de Freitas. Passos, compassos e descompassos no ensino de dança nas escolas. 2005. $93 \mathrm{f}$. Dissertação (Mestrado) - Universidade Estadual de Campinas, Campinas, 2005.

MOURA, Kátia Cristina Figueredo de. Essas bailarinas fantásticas e seus corpos maravilhosos: existe um corpo ideal para a dança? 2001. 205 f. Dissertação (Mestrado) - Universidade Estadual de Campinas, Campinas, 2001.

NANNI, Dionísia. Ensino da dança. Rio de Janeiro: Shape, 2003.

PEREIRA, Sybelle Regina Carvalho. Dança na escola: princípios didático-pedagógicos fundamentados na psicologia histórico-cultural de Vygotsky. 1997. 162 f. Dissertação (Mestrado) - Universidade Federal de Santa Maria, Santa Maria, 1997.

PREGNOLATTO, Daraína. Criandança: uma visita à metodologia de Rudolf Laban. Brasília: L. G. E, 2004. 
SADALLA, Ana Maria Falcão de Aragão et al. Teorias implícitas na ação docente: contribuição teórica ao desenvolvimento do professor prático-reflexivo. In: AZZI, Roberta Gurgel; BATISTA, Sylvia Helena de Souza Silva; SADALLA, Ana Maria Falcão de Aragão (Org.). Formação de professores: discutindo o ensino de psicologia. Campinas: Alínea, 2000.

SANTOS, Rosirene Campêlo dos; FIGUEIREDO, Valéria Maria Chaves. Dança e inclusão no contexto escolar, um diálogo possível. Revista Pensar a prática: Revista da Pós-Graduação em Educação Física, Goiânia, v. 6, p. 107-116, jul./jun. 2002-2003.

SHAPIRO, Sherry. Em direção a professores transformadores: perspectivas crítica e feminista para o ensino da dança. Revista Proposições, Campinas, v. 9, n. 2 [26], p. 35-45, 1998.

STRAZZACAPPA, Marcia. A educação e a fábrica de corpos: a dança na escola. Caderno CEDES, v. 21, n. 53, p. 69-83. abr. 2001.

Prodança-criança-escola: os projetos de ensino de dança em Campinas/SP- integrando universos. Anais da $9^{a}$ conferência da DACI. Revista da FSBA, Salvador, v. 2, p. 273-278, ago. 2003.

Recebido: 25/08/2007

Received: 08/25//2007

Aprovado: 05/11/2007

Approved: 11/05/2007

Rev. Diálogo Educ., Curitiba, v. 8, n. 23, p. 207-220, jan./abr. 2008 